Open Access

\title{
Consolidation chemotherapy may improve survival for patients with locally advanced non-small-cell lung cancer receiving concurrent chemoradiotherapy - retrospective analysis of 203 cases
}

Lipin $\mathrm{Liu}^{1}$, Nan $\mathrm{Bi}^{1}$, Zhe $\mathrm{Ji}^{1}$, Junling $\mathrm{Li}^{2}$, Jingbo Wang ${ }^{1}$, Xiaozhen Wang ${ }^{1}$, Zhouguang Hui ${ }^{1}$, Jima $\mathrm{Lv}^{1}$, Jun Liang ${ }^{1}$, Zongmei Zhou', Yan Wang ${ }^{2}$, Weibo Yin ${ }^{1}$ and Luhua Wang ${ }^{1 *}$

\begin{abstract}
Background: For patients with locally advanced non-small-cell lung cancer (LA-NSCLC), the role of consolidation chemotherapy (CCT) following concurrent chemoradiotherapy (CRT) is partially defined. The aim of this study was to evaluate the efficacy and toxicity of CCT.

Methods: The characteristics of LA-NSCLC patients treated with curative concurrent CRT from 2001 to 2010 were retrospectively reviewed.

Results: Among 203 patients, 113 (55.7 \%) patients received CCT. The median number of delivered CCT was 3 and $89.4 \%$ patients completed $\geq 2$ cycles. The OS was significantly better for patients in the CCT group compared with that in the non-CCT group (median OS, 27 months vs. 16 months; 5 -year OS, $30.4 \%$ vs. $22.5 \% ; p=0.012$ ). The median PFS were 12 months in the CCT group and 9 months in the non-CCT group $(p=0.291)$. The survival advantages of CCT were significant for males (HR: 0.63; $95 \% \mathrm{Cl}, 0.44-0.90)$, patients with age < 60 years (HR: 0.63; $95 \% \mathrm{Cl}, 0.42-0.95$ ), non-squamous histology (HR: 0.44; $95 \% \mathrm{Cl}, 0.25-0.76$ ), pretreatment KPS $\geq 80$ (HR: $0.67 ; 95 \% \mathrm{Cl}, 0.48-0.93$ ), stage IIIb (HR: $0.64 ; 95 \% \mathrm{Cl}, 0.43-0.95$ ), stable disease (HR: 0.31; $95 \% \mathrm{Cl}, 0.14-0.65$ ) and radiotherapy dose $\geq 60$ Gy (HR: 0.69; $95 \% \mathrm{Cl}, 0.48-1.00)$. There was no significant difference between the CCT group and the non-CCT group regarding treatment-related toxicities.
\end{abstract}

Conclusions: CCT might further prolong survival compared with CRT alone for LA-NSCLC without increasing treatmentrelated toxicities, especially for males, patients with age $<60$ years, non-squamous histology, pretreatment KPS $\geq 80$, stage IIIb, stable disease and radiotherapy dose $\geq 60 \mathrm{~Gy}$. Large size prospective investigations that incorporate patient characteristics and treatment response are warranted to validate our findings.

Keywords: Locally advanced, Non-small-cell lung cancer, Consolidation chemotherapy, Efficacy, Toxicity

\footnotetext{
* Correspondence: wlhwq@yahoo.com

'Department of Radiation Oncology, Cancer Hospital and Institute, Chinese

Academy of Medical Sciences \& Peking Union Medical College, Beijing

100021, China

Full list of author information is available at the end of the article
}

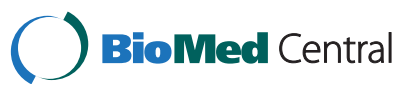

(C) 2015 Liu et al. Open Access This article is distributed under the terms of the Creative Commons Attribution 4.0 International License (http://creativecommons.org/licenses/by/4.0/), which permits unrestricted use, distribution, and reproduction in any medium, provided you give appropriate credit to the original author(s) and the source, provide a link to the Creative Commons license, and indicate if changes were made. The Creative Commons Public Domain Dedication waiver (http://creativecommons.org/publicdomain/zero/1.0/) applies to the data made available in this article, unless otherwise stated. 


\section{Background}

Lung cancer remains the leading cause of cancerrelated deaths worldwide [1]. Non-small-cell lung cancer (NSCLC) accounts for $80 \%$ of all lung cancer cases and approximately $40 \%$ of patients with NSCLC present with locally advanced non-small-cell lung cancer (LANSCLC) at diagnosis [2]. The standard-of-care treatment for LA-NSCLC is concurrent platinum-based chemotherapy and thoracic radiotherapy [3-5], which yields superior survival compared with either radiotherapy alone or sequential chemoradiotherapy. However, the outcome of LA-NSCLC treated with concurrent chemoradiotherapy (CRT) remains disappointing, with a median survival of 12-23.2 months [6, 7].

To improve survival, numerous studies have focused on exploring the feasibility and efficacy of consolidation chemotherapy (CCT) following concurrent CRT with discordant results. A phase II study of the Southwest Oncology Group (SWOG) 9504 [8] treated patients with concurrent CRT followed by consolidation docetaxel and achieved a promising median survival of 26 months suggesting a possible benefit of CCT. However, the Hoosier Oncology Group (HOG) [6], who published the only full article on a randomized phase III trial thus far, failed to replicate the encouraging outcome of SWOG 9504 by randomly delivering either docetaxel or observation after CRT. A recent pooled analysis [2] of 45 studies showed that CCT provided no survival benefit for LA-NSCLC patients. However, a subgroup analysis demonstrated that Asian populations (mostly from Japan and Korea) tended to benefit from $\mathrm{CCT}$, although this benefit did not meet statistical significance $(\mathrm{HR}=0.84 ; 95 \% \mathrm{CI}$, $0.68-1.04 ; p=0.105)$. Given the lack of substantial evidence from randomized phase III clinical trials, the definitive role of CCT in LA-NSCLC is unknown, especially in the Asian population. Therefore, our study attempted to evaluate the efficacy and toxicity of CCT after concurrent CRT at our institution.

\section{Methods}

\section{Ethics statement}

This retrospective study was approved by the ethics committee of the Cancer Hospital and Institute of Chinese Academy of Medical Sciences \& Peking Union Medical College. Informed consent was exempted by the board due to the retrospective nature of this research. Patient records were anonymized and de-identified prior to analysis.

\section{Eligibility}

We retrospectively reviewed the clinical records of LANSCLC patients treated with concurrent CRT as an initial treatment at out institution between January 2001 and December 2010. The criteria for inclusion were defined as follows: (1) histologically or cytologically proven
NSCLC; (2) clinically diagnosed as stage III disease according to the American Joint Committee on Cancer (AJCC) 2009 staging system; (3) treated with curative thoracic radiotherapy of no less than 50 Gy using intensity modulated radiotherapy (IMRT) or three-dimensional conformal radiotherapy (3D-CRT) with concurrent platinum doublet chemotherapy; (4) treatment responses evaluated 1 month after the completion of concurrent CRT in accordance with the Response Evaluation Criteria for Solid Tumors (RECIST) version 1.1 as complete response $(\mathrm{CR})$, partial response (PR), and stable disease (SD).

\section{Evaluation and follow-up}

Complete blood cell counts (CBCs) and blood chemistry examinations were repeated once per week during the treatment period. The follow-up evaluations consisted of a physical examination, $\mathrm{CBC}$, serum biochemistry, tumor marker, thoracic computed tomography $(\mathrm{CT})$ scans, abdomen B-ultrasound examination, and other necessary imaging examinations as clinically indicated at intervals of 3 months for the first year, then every 6 months for the following 2 years, and annually thereafter. Local recurrence was defined as primary tumor recurrence, and regional recurrence was defined as recurrence in the mediastinum, hilum and supraclavicular fossa. Other sites of recurrence, including contralateral lung and metastatic lymph nodes in the neck or axilla, were defined as distant metastasis. Disease progression was determined based on a radiologic examination, histologic examination, or both. Treatment toxicities were graded according to the Common Terminology Criteria for Adverse Events (CTCAE) version 3.0.

\section{Data analysis}

Overall survival (OS) was defined from the beginning of concurrent CRT to the time of death due to any cause or last follow-up. Cancer specific survival (CSS) was defined from the beginning of concurrent CRT to the time of death due to lung cancer or last follow-up. Progressionfree survival (PFS) was defined from the beginning of concurrent CRT to the time of tumor progression or last follow-up. Local regional progression-free survival (LRPFS) was defined from the beginning of concurrent CRT to the time of local regional progression or last follow-up. Distant metastasis-free survival (DMFS) was defined from the beginning of concurrent CRT to the time of appearance of metastatic disease or last follow-up. Survival analysis was performed using the Kaplan-Meier method and log-rank test. Univariate and multivariate analyses by use of a Cox-proportional hazards model were performed to evaluate potential prognostic factors for OS and PFS. Variables with $p<0.3$ in univariate analyses were entered into multivariate analyses. The Pearson $\chi^{2}$ test was used to compare the baseline characteristics and 
incidence of specific toxicities between treatment groups. Cox proportional hazards models, stratified by age, sex, histology, pretreatment Karnofsky performance score (KPS), stage, treatment response and radiotherapy dose were used to estimate HRs and $95 \%$ confidence intervals (CIs) and test for significance for OS. A statistically significant difference was defined as $p<0.05$. All data were processed with SPSS version 19.0.

\section{Results}

\section{Patient characteristics}

This retrospective study identified 261 consecutive LANSCLC patients who received concurrent chemotherapy and curative thoracic radiotherapy with a radiation dose $\geq 50$ Gy at our institution between January 2001 and December 2010. We excluded 17 patients whose response assessments were unavailable, 13 patients who experienced disease progression within a month after concurrent CRT, 18 patients whose concurrent chemotherapy did not consist of platinum doublet regimens and 10 patients who were treated with conventional two-dimensional radiotherapy; thus, a total of 203 patients were available for analysis. The characteristics of the 203 patients are presented in Table 1 . The median follow-up time was 23 months (range, 2-130 months) for the entire study population and 58.5 months (range, 10-130 months) for censored patients. The median age of the patients was 56 years (range, 31-73 years). The majority of patients were male ( $83.7 \%$ ) and younger than 60 years old $(64 \%)$ with no significant $(<5 \%)$ weight loss $(82 \%)$ and a smoking index $>400$ (60.6\%). $94.6 \%$ of patients had a pretreatment KPS $\geq 80$, and $66.5 \%$ of patients presented with stage IIIb disease. Most patients had normal hemoglobin $(95.6 \%)$ and carcinoembryonic antigen (CEA) $(67.1 \%)$ levels at diagnosis. The most common histology subtype was squamous cell carcinoma (SCC) (65.5\%). Only $26.1 \%$ of patients had positron emission tomography (PET) scan staging.

Of all 203 patients, $161(79.3 \%)$ were treated with IMRT and $42(20.7 \%)$ were treated with 3D-CRT. The radiation area only included the involved fields. The median radiation dose was 60 Gy in 30 fractions (range, 50-74 Gy in 25-37 fractions). For the concurrent chemotherapy regimen, 99 (48.8\%) patients were administered EP (etoposide plus cisplatin), 87 (42.8 \%) patients received PC (paclitaxel plus carboplatin) and 17 $(8.4 \%)$ patients were treated with other platinumdoublet regimens. The responses of CR, PR, and SD were observed in $5(2.5 \%)$ patients, 161 (79.3\%) patients and 37 (18.2 \%) patients, respectively. After concurrent CRT, 113 (55.7 \%) patients received CCT, including 88 patients with platinum-based doublet chemotherapy regimens, and 25 patients with single-agent regimens. Among 113 patients who received CCT, the median number of delivered
Table 1 Patient characteristics

\begin{tabular}{|c|c|c|c|}
\hline Characteristic & Non-CCT (\%) & CCT (\%) & $p$-value \\
\hline \multicolumn{4}{|l|}{ Gender } \\
\hline Male & $83(92.2)$ & $87(77.0)$ & 0.003 \\
\hline Female & $7(7.8)$ & $26(23.0)$ & \\
\hline Age & & & 0.005 \\
\hline$<60$ years & $48(53.3)$ & $82(72.6)$ & \\
\hline$\geq 60$ years & $42(46.7)$ & $31(27.4)$ & \\
\hline Weight loss & & & 0.941 \\
\hline$<5 \%$ & $74(82.2)$ & $90(81.8)$ & \\
\hline$\geq 5 \%$ & $16(17.8)$ & $20(18.2)$ & \\
\hline Smoking index ${ }^{a}$ & & & 0.031 \\
\hline$\leq 400$ & $28(31.1)$ & $52(46.0)$ & \\
\hline$>400$ & $62(68.9)$ & $61(54.0)$ & \\
\hline Pretreatment hemoglobin & & & 0.306 \\
\hline$<120 \mathrm{~g} / \mathrm{L}$ & $2(2.2)$ & $7(6.2)$ & \\
\hline$\geq 120 \mathrm{~g} / \mathrm{L}$ & $88(97.8)$ & $106(93.8)$ & \\
\hline Pretreatment KPS & & & 0.697 \\
\hline$<80$ & $6(6.7)$ & $5(4.4)$ & \\
\hline$\geq 80$ & $84(93.3)$ & $108(95.6)$ & \\
\hline Stage & & & 0.146 \\
\hline Illa & $35(38.9)$ & $33(29.2)$ & \\
\hline$\| l l b$ & $55(61.1)$ & $80(70.8)$ & \\
\hline Histology subtype & & & 0.545 \\
\hline SCC & $61(67.8)$ & $72(63.7)$ & \\
\hline Non-SCC & $29(32.2)$ & $41(36.3)$ & \\
\hline Pretreatment CEA & & & 0.729 \\
\hline$<5 \mathrm{ng} / \mathrm{ml}$ & $50(68.5)$ & $62(66.0)$ & \\
\hline$\geq 5 \mathrm{ng} / \mathrm{ml}$ & $23(31.5)$ & $32(34.0)$ & \\
\hline \multicolumn{4}{|l|}{ PET scan staging } \\
\hline Yes & $25(27.8)$ & $28(24.8)$ & 0.629 \\
\hline No & $65(72.2)$ & $85(75.2)$ & \\
\hline Radiotherapy technique & & & 0.010 \\
\hline 3D-CRT & $26(28.9)$ & $16(14.2)$ & \\
\hline IMRT & $64(71.1)$ & $97(85.8)$ & \\
\hline Radiotherapy dose & & & 0.342 \\
\hline$\geq 60$ Gy & $71(78.9)$ & $95(84.1)$ & \\
\hline$<60$ Gy & $19(21.1)$ & $18(15.9)$ & \\
\hline Concurrent chemotherapy & & & 0.010 \\
\hline EP & $36(40.0)$ & $63(55.8)$ & \\
\hline PC & $49(54.4)$ & 38 (33.6) & \\
\hline others & $5(5.6)$ & $12(10.6)$ & \\
\hline Response & & & 0.559 \\
\hline$C R+P R$ & $72(80.0)$ & $94(83.2)$ & \\
\hline SD & $18(20.0)$ & 19 (16.8) & \\
\hline
\end{tabular}

CCT consolidation chemotherapy, CEA carcinoembryonic antigen, KPS Karnofsky performance status, PET positron emission tomography, SCC squamous cell carcinoma

${ }^{\mathrm{a}}$ Smoking index is the number of cigarettes smoked per day $\times$ the number of cigarette-years 
CCT was 3 and $101(89.4 \%)$ patients completed $\geq 2$ cycles of CCT.

As shown in Table 1, females (23\% vs. $7.8 \% ; p=0.003)$, patients aged $<60$ years $(72.6 \%$ vs. $53.3 \% ; p=0.005)$ with a smoking index $\leq 400$ (46\% vs. $31.1 \% ; p=0.031$ ) who received IMRT (85.8 \% vs. $71.1 \% ; p=0.010$ ) and concurrent EP chemotherapy (55.8\% vs. $40 \% ; p=0.010$ ) were more prevalent in the CCT group than in the non-CCT group. The remaining listed clinical characteristics were comparable between the two groups.

\section{Survival and prognostic factors}

The median OS and 5-year OS for all patients were 24 months and $26.9 \%$, respectively. Patients in the CCT group achieved significant survival prolongation compared with those in the non-CCT group (median OS, 27 months vs. 16 months; 5 -year OS, $30.4 \%$ vs. $22.5 \%$; $p=0.012$; Fig. 1a). The median CSS and 5-year CSS for the CCT group (28 months and $34.4 \%$ ) in our study were also superior to those for the non-CCT group (17 months and $27.9 \%)(p=0.022)$, which was consistent with the OS results. The median PFS and 5-year PFS were 12 months and $21.8 \%$ in the CCT group and 9 months and $21.4 \%$ in the non-CCT group, respectively ( $p=0.291$; Fig. $1 \mathrm{~b})$. The 5 -year LRPFS were $37.3 \%$ in the CCT group and $35.1 \%$ in the non-CCT group ( $p=0.265$; Fig. $1 c)$. The 5 -year DMFS were $40.1 \%$ in the CCT group and $42.2 \%$ in the non-CCT group ( $p=0.779$; Fig. $1 \mathrm{~d})$.

The results of the univariate and multivariate analyses of potential prognostic factors for OS are shown in Table 2. Univariate analysis identified the radiotherapy dose $<$ 60 Gy $(p=0.014)$, no CCT $(p=0.012)$ and SD $(p=0.035)$ as significant unfavorable prognostic factors. Multivariate analysis identified pretreatment CEA $\geq 5 \mathrm{ng} / \mathrm{ml}(p=$ $0.047)$, no CCT delivery $(p=0.008)$, and SD $(p=0.036)$ as predictors for poor OS. Additional file 1: Table S1 shows the results of the univariate and multivariate analyses of potential prognostic factors for PFS. The univariate analysis showed superior PFS for patients with SCC histology $(p=0.013)$, normal pretreatment CEA $(p=0.000)$, radiotherapy dose $\geq 60$ Gy $(p=0.019)$ and CR or PR $(p=0.049)$. In the multivariate analysis, age $<60$ years $(p=0.012)$, pretreatment CEA $\geq 5 \mathrm{ng} / \mathrm{ml}(p=0.000)$, and no CCT delivery $(p=0.022)$ were significantly associated with unfavorable PFS.

In the subgroup analysis, the median OS and 5-year OS for patients receiving $\geq 2$ cycles of CCT (27 months and $31.8 \%)$ were better than those administered with $<2$ cycles of CCT (22 months and $18.7 \%)(p=0.317)$. The median time interval between completion of CRT to CCT was 6 weeks. The median OS and 5-year OS for patients with intervals $\leq 6$ weeks ( 28 months and $34.4 \%$ ) were not statistically different from those with intervals $>6$ weeks $(25$ months and $24 \%)(p=0.281)$. A forest plot of HRs for OS stratified by study characteristics is shown in Fig. 2. The survival advantages of CCT were statistically significant for males (HR: 0.63; $95 \%$ CI, 0.44$0.90 ; p=0.011$ ), patients with age $<60$ years (HR: 0.63 ; $95 \%$ CI, 0.42-0.95; $p=0.027)$, non-squamous histology (HR: $0.44 ; 95 \% \mathrm{CI}, 0.25-0.76 ; p=0.003$ ), pretreatment KPS $\geq 80$ (HR: 0.67; $95 \%$ CI, 0.48-0.93; $p=0.017$ ), stage IIIb (HR: 0.64; $95 \%$ CI, 0.43-0.95; $p=0.025$ ), SD (HR: $0.31 ; 95 \% \mathrm{CI}, 0.14-0.65 ; p=0.002)$ and radiotherapy dose $\geq 60$ Gy (HR: 0.69; $95 \%$ CI, $0.48-1.00 ; p=0.048$ ).

\section{Toxicity}

The treatment-related acute toxicities during the CRT and the CCT phase are listed in Table 3. The incidence of grade $\geq 3$ hematological toxicities between the CCT group and the non-CCT group was similar (30.1 \% vs. $34.4 \% ; p=0.509)$ during the CRT phase. In patients receiving CCT, $15 \%$ experienced grade $\geq 3$ hematological toxicities during the CCT phase and no patient had grade 5 hematological toxicities. The incidence of grade $\geq 3$ esophagitis was comparable between the CCT group and the non-CCT group during the CRT phase $(9.7 \%$ vs. $13.3 \% ; p=0.422)$. Grade $\geq 3$ radiation pneumonitis occurred at similar rates between the CCT and the non-CCT group during the CRT (0.0 \% vs. $2.2 \% ; p=0.195)$ and CCT phase (5.3\% vs. $3.3 \% ; p=0.737$ ). A total of 4 patients died of grade 5 radiation pneumonitis, including $2(2.2 \%)$ in the CCT group and 2 in the non-CCT (1.8\%) group.

\section{Discussion}

The outcomes of LA-NSCLC are relatively poor, with a high possibility of residual disease after definitive CRT. Thus, many clinical trials have investigated the role of additional CCT. To date, three randomized phase III studies $[6,9,10]$ have been carried out to explore the efficacy and toxicity of CCT, among which only one has been published as a full article. HOG [6] reported that consolidation docetaxel yielded no survival benefit (median OS, 21.2 months vs. 23.2 months; $p=0.883$ ) with an increased risk for grade $3 / 4$ pneumonitis (9.6 \% vs. $1.4 \% ; p<0.001)$, infections (11\% vs. $0 \% ; p=0.003)$, hospitalization ( $28.8 \%$ vs. $8.1 \%)$ and treatment-related death $(5.5 \%$ vs. $0 \% ; p=0.058)$. In the GILT [9] study, consolidation oral vinorelbine (NVBo) and cisplatin (P) after NVBo plus $\mathrm{P}$ failed to prolong the median PFS (6.4 months vs. 5.5 months; $p=0.630$ ) and 4-year OS (25.3\% vs. $21.4 \%$ ). The multinational CCheIN trial [10] reported that consolidation DP (docetaxel plus cisplatin) after concurrent weekly DP resulted in a PFS (median PFS, 9.1 months vs. 8.1 months; $p=0.390$ ) and a OS (median OS, 21.8 months vs. 20.6 months; $p=0.490$ ) that were similar to those of the observation group. A recently reported pooled-analysis including forty-one 
A
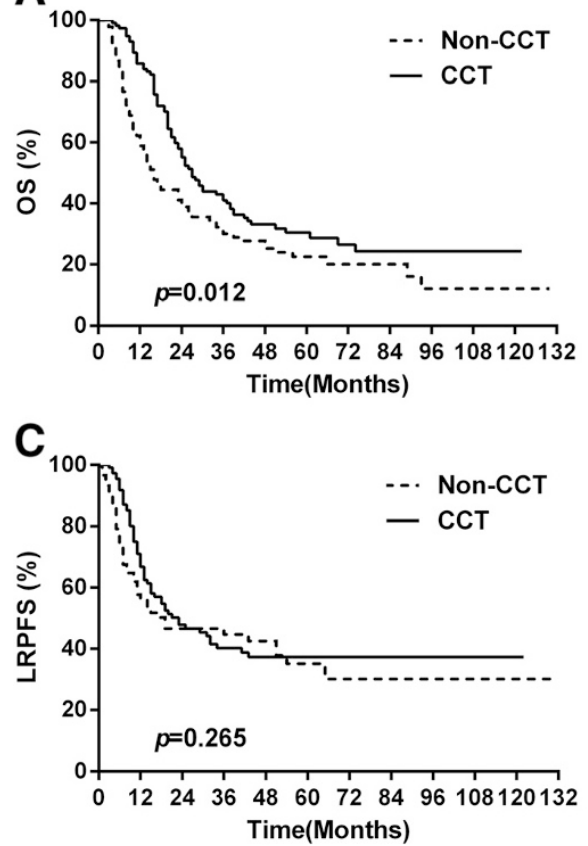

B

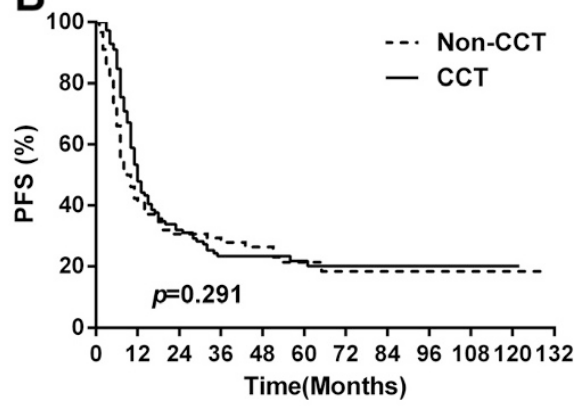

D

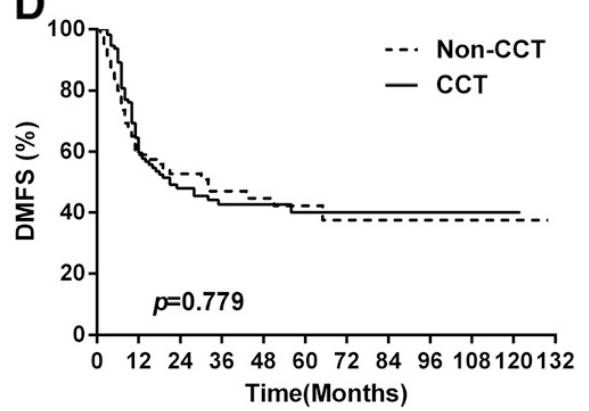

Fig. 1 Comparison of a overall survival (OS), b progression-free survival (PFS), c local regional progression-free survival (LRPFS) and d distant metastasis-free survival (DMFS) between the consolidation chemotherapy (CCT) and non-CCT groups

phase II/III studies with 3479 patients also failed to provide significant survival benefit of CCT for LA-NSCLC. Unlike HOG, the GILT study and CCheIN trial observed that the addition of CCT did not increase the toxicities. Despite the negative results mentioned above, many oncologists still attempt to deliver CCT for LA-NSCLC patients with good performance status after CRT in routine clinical practice, at least partially due to a poor survival rate of less than $20 \%$ at 5 years and a significant survival benefit achieved by CCT in stage IV disease.

The long-term results of this retrospective study suggest that CCT further prolongs survival compared with CRT alone for LA-NSCLC without increased toxicities. Although more patients in the CCT group had a positive selection factors (female, younger age and a lighter history of smoking), the multivariate analysis was able to account for those selection bias and showed that CCT was a positive prognostic factor for OS and PFS. For patients in the CCT group, the encouraging median OS and 5-year OS were 27 months and $30.4 \%$, respectively, which were superior to those reported in randomized clinical trials $[6,9,10]$ and comparable to the survival results in SWOG 9504. The median OS and 5-year OS were 16 months and $22.5 \%$, respectively, in the nonCCT group, which were similar to the historical controls $[4,7]$. Although there was no difference regarding LRPFS or DMFS between the CCT group and the non-CCT group, CCT prolonged survival compared with CRT alone, which may be attributed to several reasons as follows. First, the multivariate analysis for PFS showed that CCT was an independent favorable prognostic factor $(\mathrm{HR}=$ 0.643; $95 \% \mathrm{CI}, 0.441-0.937 ; p=0.022$ ), though we found that the LRPFS $(p=0.265)$ and DMFS $(p=0.779)$ outcomes were similar between the CCT and non-CCT group. The improvement in disease control may translate into improved survival. The improvement in disease control may translate into improved survival. The multivariate analysis for PFS showed that CCT was an independent favorable prognostic factor $(\mathrm{HR}=0.643$; $95 \% \mathrm{CI}, 0.441-$ 0.937; $p=0.022$ ). A second explanation is that ethnicity may affect the efficacy of CCT. Our result is consistent with a recent pooled analysis [2] that suggested that survival was better in Asian patients when CCT was delivered, though this improvement was not statistically significant. Soo et al.[11] reported that the survival and response rate to chemotherapy were better in Asian patients with lung cancer, while the treatment-related toxicities were more severe than in Caucasian patients. To date, the exact mechanisms with which ethnicity affects the efficacy of CCT are unknown. The interethnic difference may be attributable to differences in the genetic backgrounds or environment and culture. Third, it should be noted that the actually delivered cycles of CCT in most studies were relatively lower ( 0.7 to 3.1 , average: 1.5$)$ than those observed in our study (the median number was 3 and $89.4 \%$ of patients completed $\geq 2$ cycles of CCT). 
Table 2 Results of the univariate and multivariate analyses of prognostic factors for OS

\begin{tabular}{|c|c|c|c|c|c|c|}
\hline \multirow[b]{2}{*}{ Characteristic } & \multicolumn{3}{|c|}{ Univariate analysis } & \multicolumn{3}{|c|}{ Multivariate analysis } \\
\hline & MST (mos) & 5 -yr OS (\%) & $p$-value & $H R$ & $95 \% \mathrm{Cl}$ & $p$-value \\
\hline Gender & & & 0.431 & & & \\
\hline Male & 23 & 27.4 & & & & \\
\hline Female & 28 & 24.5 & & & & \\
\hline Age & & & 0.834 & & & \\
\hline$<60$ years & 24 & 26.5 & & & & \\
\hline$\geq 60$ years & 21 & 27.6 & & & & \\
\hline Weight loss & & & 0.292 & 1.01 & $0.61-1.66$ & 0.977 \\
\hline$<5 \%$ & 24 & 28.7 & & & & \\
\hline$\geq 5 \%$ & 24 & 20.2 & & & & \\
\hline Smoking index & & & 0.399 & & & \\
\hline$\leq 400$ & 26 & 26.5 & & & & \\
\hline$>400$ & 20 & 27.4 & & & & \\
\hline Pretreatment hemoglobin & & & 0.580 & & & \\
\hline$<120 \mathrm{~g} / \mathrm{L}$ & 35 & - & & & & \\
\hline$\geq 120 \mathrm{~g} / \mathrm{L}$ & 24 & 26.8 & & & & \\
\hline Pretreatment KPS & & & 0.096 & 0.68 & $0.34-1.37$ & 0.285 \\
\hline$<80$ & 16 & 9.1 & & & & \\
\hline$\geq 80$ & 24 & 28.0 & & & & \\
\hline Stage & & & 0.303 & & & \\
\hline Illa & 27 & 31.1 & & & & \\
\hline Illb & 23 & 24.9 & & & & \\
\hline Histology subtype & & & 0.848 & & & \\
\hline SCC & 24 & 28.0 & & & & \\
\hline Non-SCC & 24 & 25.1 & & & & \\
\hline Pretreatment CEA & & & 0.076 & 0.67 & $0.45-0.99$ & 0.047 \\
\hline$<5 \mathrm{ng} / \mathrm{ml}$ & 27 & 30.9 & & & & \\
\hline$\geq 5 \mathrm{ng} / \mathrm{ml}$ & 23 & 18.3 & & & & \\
\hline Radiotherapy technique & & & 0.128 & 1.09 & $0.66-1.79$ & 0.743 \\
\hline 3D-CRT & 18 & 16.2 & & & & \\
\hline IMRT & 25 & 30.1 & & & & \\
\hline Radiotherapy dose & & & 0.014 & 0.66 & $0.42-1.04$ & 0.071 \\
\hline$\geq 60$ Gy & 25 & 29.5 & & & & \\
\hline$<60$ Gy & 19 & 14.9 & & & & \\
\hline \multicolumn{7}{|l|}{ Concurrent chemotherapy } \\
\hline EP & 27 & 29.8 & 0.365 & & & \\
\hline PC & 19 & 24.0 & & & & \\
\hline Others & 25 & - & & & & \\
\hline Treatment modality & & & .012 & 0.61 & $0.42-0.88$ & 0.008 \\
\hline $\mathrm{CRT}+\mathrm{CCT}$ & 27 & 30.4 & & & & \\
\hline CRT & 16 & 22.5 & & & & \\
\hline Response & & & 0.035 & 0.62 & $0.40-0.97$ & 0.036 \\
\hline$C R+P R$ & 24 & 29.7 & & & & \\
\hline SD & 21 & 10.6 & & & & \\
\hline
\end{tabular}




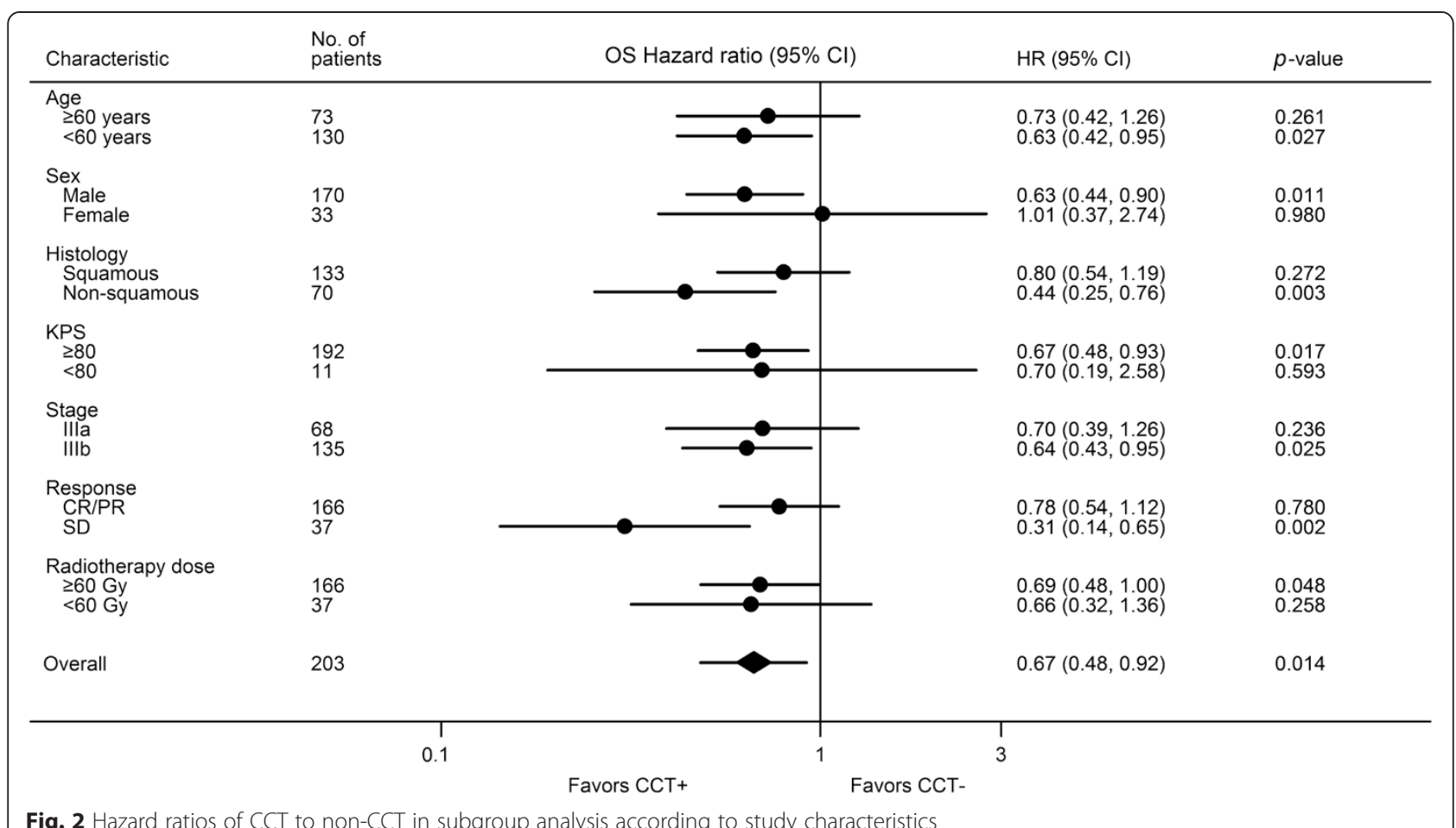

Last, bias may be involved in such a retrospective study. The choice of oncologists and patients may influence the administration of CCT. Treatment compliance was higher in patients in the CCT group than in those in the nonCCT group because some patients refused CCT despite the oncologists' suggestion. Treatment compliance could impact patients' routine follow up and motivation for salvage treatment after progression, which influences the outcome. The reason why CCT resulted in no significant increase in toxicities may be increased use of IMRT (85.8 \% vs. $71.1 \% ; p=0.010)$ and timely management of toxicity, as IMRT may decrease esophageal and pulmonary toxicity compared with $3 \mathrm{D}$-CRT by increasing target conformity $[12,13]$.

Our study also suggested that CCT may lead to significant OS benefit for males, patients with age $<$ 60 years, non-squamous histology, pretreatment $\mathrm{KPS} \geq$ 80 , stage IIIb, SD and radiotherapy dose $\geq 60 \mathrm{~Gy}$. It seems plausible that fit patients with higher risk of distant metastasis would benefit from CCT. Interestingly, the fact that the $\mathrm{HR}$ for patients achieving SD is favoring CCT, which is contrary to Jeremic [14]

Table 3 Treatment-related toxicities

\begin{tabular}{|c|c|c|c|c|c|c|c|c|}
\hline \multirow[t]{2}{*}{ Toxicity } & \multicolumn{4}{|l|}{ CRT phase } & \multicolumn{4}{|l|}{ CCT phase } \\
\hline & CCT $(\%)$ & Non-CCT (\%) & Total & $p$-value & $\mathrm{CCT}(\%)$ & Non-CCT (\%) & Total & $p$-value \\
\hline Hematological & & & & 0.509 & & & & - \\
\hline Grade 3/4 & $34(30.1)$ & $31(34.4)$ & $65(32.0)$ & & $17(15.0)$ & - & - & \\
\hline Grade 1/2 & 79 (69.9) & $59(65.6)$ & $138(68.0)$ & & $96(85.0)$ & - & - & \\
\hline Esophagitis & & & & 0.422 & & & & - \\
\hline Grade 3 & $11(9.7)$ & $12(13.3)$ & $23(11.3)$ & & - & - & - & \\
\hline Grade 1/2 & $102(90.3)$ & $78(86.7)$ & $180(88.7)$ & & - & - & - & \\
\hline Radiation pneumonitis & & & & 0.195 & & & & \\
\hline Grade $\geq 3$ & $0(0.0)$ & $2(2.2)$ & $2(1.0)$ & & $6(5.3)$ & $3(3.3)$ & $9(4.4)$ & 0.737 \\
\hline Grade 1/2 & $113(100.0)$ & $88(97.8)$ & $201(99.0)$ & & $107(94.7)$ & $87(96.7)$ & 194 (95.6) & \\
\hline
\end{tabular}


holding the view that patients with a CR or a PR rather than those with a SD were likely to benefit from CCT. However, the number of patients with SD in our study was too small to draw a conclusion.

Prognostic factors are essential to understand the disease process, select treatments and design clinical trials. Numerous studies have investigated the prognostic factors for LA-NSCLC with inconsistent results. The commonly recognized favorable prognostic factors include stage IIIa, good performance status, non-significant weight loss, and female gender [15-17]. In our study, the multivariate analyses identified pretreatment CEA $\geq$ $5 \mathrm{ng} / \mathrm{ml}$, no CCT, and SD after CRT as predictive of worse OS. Age $<60$ years, pretreatment CEA $\geq 5 \mathrm{ng} / \mathrm{ml}$, and no CCT were significantly associated with poor PFS. Our study did not show a significant association between OS or PFS and the widely recognized prognostic factors mentioned above, which may be the result of a relatively small sample size and under-representation of patients with pretreatment KPS $<80(5.4 \%)$ and weight loss $\geq 5 \%$ (18\%).

Similar to our results, a retrospective study [18] reported that the clinical tumor response was significantly associated with OS. Kim et al. [19] found a five-fold likelihood of long term survival for responders (CR or PR) compared to non-responders (SD or PD) $(p=0.067)$. Because the clinical tumor response can be assessed soon after CRT, this approach may aid in the following treatment decision according to clinical tumor response to initial CRT because non-responders may need more aggressive treatment.

The prognostic role of age for LA-NSCLC is contradictory. A Radiation Therapy Oncology Group (RTOG)-based analysis [17] found that age $\leq 70$ years was associated with improved survival. Nevertheless, the secondary analysis of RTOG 9410 [20] demonstrated that in patients treated with CRT, the median OS was longer for patients aged $\geq$ 70 years (22.4 months vs. 15.5 months, $p$-value not provided). Numerous recent trials [21-23] suggested that CRT yielded similar treatment outcome for fit older patients compared with younger patients, which agreed with our results that the elderly (age $\geq 60$ years) were noninferior to the young (age $<60$ years) with respect to OS. The reason why age $<60$ years acted as a negative predictor for PFS is unknown. The difference in the biological behavior between younger and older patients warrants further investigation.

Although our study is based on a relatively large sample size with a long follow-up period, it has some limitations. Like all other retrospective studies, our study is inevitably subject to multiple biases. Moreover, the CCT regimens were largely heterogeneous, which hindered our study from further exploring the most effective CCT regimen.

\section{Conclusions}

This retrospective study suggested that CCT further prolonged survival compared with CRT alone for LANSCLC without increasing treatment-related toxicities. Subgroup analysis identified that the survival advantages of CCT were more significant for males, patients with age $<60$ years, non-squamous histology, pretreatment KPS $\geq 80$, stage IIIb, SD and radiotherapy dose $\geq 60$ Gy. Further prospective investigations that incorporate patient characteristics and treatment response are needed to validate our results.

\section{Additional file}

Additional file 1: Table S1. Results of the univariate and multivariate analyses of prognostic factors for PFS. (DOCX 20 kb)

\section{Abbreviations}

3D-CRT: Three-dimensional conformal radiotherapy; AJCC: American joint committee on cancer; CBC: Complete blood cell count; CCT: Consolidation chemotherapy; CEA: Carcinoembryonic antigen; Cl: Confidence interval; CR: Complete response; CRT: Concurrent chemoradiotherapy; CSS: Cancer specific survival; CTCAE: Common terminology criteria for adverse events; DMFS: Distant metastasis-free survival; DP: Docetaxel plus cisplatin; EP: Etoposide plus cisplatin; HOG: Hoosier oncology group; IMRT: Intensity modulated radiotherapy; KPS: Karnofsky performance score; LA-NSCLC: Locally advanced non-small-cell lung cancer; LRPFS: Local regional progression-free survival; NVBo: Oral vinorelbine; OS: Overall survival; P: Cisplatin; PC: Paclitaxel plus carboplatin; PET: Positron emission tomography; PFS: Progression-free survival; PR: Partial response; RECIST: Response evaluation criteria for solid tumors; RTOG: Radiation therapy oncology group; SCC: Squamous cell carcinoma; SD: Stable disease; SWOG: Southwest oncology group.

\section{Competing interests}

The authors declare that they have no competing interests.

\section{Authors' contributions}

LL participated in acquisition of data, analysis and interpretation of data, and drafting of the manuscript. NB, ZJ, J.Li, JW, XW, ZH, J.LV, J.Liang, ZZ, YW, WY carried out the study during clinical observation, follow up, collected the clinical data for analysis. LW conceived of the study, participated in its design and coordination and revised the final manuscript. All authors have read and approved the final manuscript.

\section{Acknowledgements}

This work was supported by the National Natural Science Foundation of China (81272616).

\section{Author details}

'Department of Radiation Oncology, Cancer Hospital and Institute, Chinese Academy of Medical Sciences \& Peking Union Medical College, Beijing 100021, China. ${ }^{2}$ Department of Medical Oncology, Cancer Hospital and Institute, Chinese Academy of Medical Sciences \& Peking Union Medical College, Beijing 100021, China.

Received: 25 January 2015 Accepted: 8 October 2015

Published online: 16 October 2015

\section{References}

1. Jemal A, Bray F, Center MM, Ferlay J, Ward E, Forman D. Global cancer statistics. CA Cancer J Clin. 2011;61(2):69-90.

2. Tsujino K, Kurata T, Yamamoto S, Kawaguchi T, Kubo A, Isa S, et al. Is consolidation chemotherapy after concurrent chemo-radiotherapy beneficial for patients with locally advanced non-small-cell lung cancer? A pooled analysis of the literature. J Thorac Oncol. 2013;8(9):1181-9. 
3. Auperin A, Le Pechoux C, Rolland E, Curran WJ, Furuse K, Fournel P, et al. Meta-analysis of concomitant versus sequential radiochemotherapy in locally advanced non-small-cell lung cancer. J Clin Oncol. 2010;28(13): 2181-90.

4. Curran Jr WJ, Paulus R, Langer CJ, Komaki R, Lee JS, Hauser S, et al. Sequential vs. concurrent chemoradiation for stage III non-small cell lung cancer: randomized phase III trial RTOG 9410. J Natl Cancer Inst. 2011;103(19):1452-60.

5. Dillman RO, Herndon J, Seagren SL, Eaton Jr WL, Green MR. Improved survival in stage III non-small-cell lung cancer: seven-year follow-up of cancer and leukemia group B (CALGB) 8433 trial. J Natl Cancer Inst. 1996;88(17):1210-5.

6. Hanna N, Neubauer M, Yiannoutsos C, McGarry R, Arseneau J, Ansari R, et al. Phase III study of cisplatin, etoposide, and concurrent chest radiation with or without consolidation docetaxel in patients with inoperable stage III non-small-cell lung cancer: the Hoosier Oncology Group and U.S. Oncology. J Clin Oncol. 2008;26(35):5755-60.

7. Vokes EE, Herndon 2nd JE, Kelley MJ, Cicchetti MG, Ramnath N, Neill H, et al. Induction chemotherapy followed by chemoradiotherapy compared with chemoradiotherapy alone for regionally advanced unresectable stage III Non-small-cell lung cancer: Cancer and Leukemia Group B. J Clin Oncol. 2007;25(13):1698-704.

8. Gandara DR, Chansky K, Albain KS, Gaspar LE, Lara Jr PN, Kelly K, et al. Long-term survival with concurrent chemoradiation therapy followed by consolidation docetaxel in stage IIIB non-small-cell lung cancer: a phase II Southwest Oncology Group Study (S9504). Clin Lung Cancer. 2006;8(2):116-21.

9. Huber RM, Engel-Riedel W, Kollmeier J, Andreas S, Staar S, Klautke G, et al. GILT study: Oral vinorelbine (NVBo) and cisplatin (P) with concomitant radiotherapy $(\mathrm{RT})$ followed by either consolidation $(\mathrm{C})$ with NVBo plus $\mathrm{P}$ plus best supportive care (BSC) or BSC alone in stage (st) III non-small cell lung cancer (NSCLC): Final results of a phase (ph) III study. J Clin Oncol. 2012;30(15s):7001.

10. Park K, Ahn Y, Ahn J, Ahn M, Kim J, Cho E, et al. A multinational phase III randomized trial with or without consolidation chemotherapy using docetaxel and cisplatin after concurrent chemoradiation in inoperable stage III non-small cell lung cancer (CCheIN). J Clin Oncol. 2014;32(15s):7500.

11. Soo RA, Kawaguchi T, Loh M, Ou SH, Shieh MP, Cho BC, et al. Differences in outcome and toxicity between Asian and caucasian patients with lung cancer treated with systemic therapy. Future Oncol. 2012;8(4):451-62.

12. Harris JP, Murphy JD, Hanlon AL, Le QT, Loo Jr BW, Diehn M. A population-based comparative effectiveness study of radiation therapy techniques in stage III non-small cell lung cancer. Int J Radiat Oncol Biol Phys. 2014;88(4):872-84.

13. Liao ZX, Komaki RR, Thames Jr HD, Liu HH, Tucker SL, Mohan R, et al. Influence of technologic advances on outcomes in patients with unresectable, locally advanced non-small-cell lung cancer receiving concomitant chemoradiotherapy. Int J Radiat Oncol Biol Phys. 2010;76(3):775-81.

14. Jeremic B. Consolidation chemotherapy after concurrent radiochemotherapy in locally advanced non-small-cell lung cancer may have been beneficial if we only knew where it have worked. J Thorac Oncol. 2014;9(1):e7.

15. Goldstraw P, Crowley J, Chansky K, Giroux DJ, Groome PA, Rami-Porta R, et al. The IASLC Lung Cancer Staging Project: proposals for the revision of the TNM stage groupings in the forthcoming (seventh) edition of the TNM Classification of malignant tumours. J Thorac Oncol. 2007;2(8):706-14.

16. Stanley KE. Prognostic factors for survival in patients with inoperable lung cancer. J Natl Cancer Inst. 1980;65(1):25-32.

17. Werner-Wasik M, Scott C, Cox JD, Sause WT, Byhardt RW, Asbell S, et al. Recursive partitioning analysis of 1999 Radiation Therapy Oncology Group (RTOG) patients with locally-advanced non-small-cell lung cancer (LA-NSCLC): identification of five groups with different survival. Int J Radiat Oncol Biol Phys. 2000;48(5):1475-82

18. Lee DS, Kim YS, Kang JH, Lee SN, Kim YK, Ahn MI, et al. Clinical Responses and Prognostic Indicators of Concurrent Chemoradiation for Non-small Cell Lung Cancer. Cancer Res Treat. 2011;43(1):32-41.

19. Kim DW, Shyr Y, Shaktour B, Akerley W, Johnson DH, Choy H. Long term follow up and analysis of long term survivors in patients treated with paclitaxel-based concurrent chemo/radiation therapy for locally advanced non-small cell lung cancer. Lung Cancer. 2005;50(2):235-45.
20. Langer C, Hsu C, Curran W, Komaki R, Lee J, Byhardt R, et al. Do elderly patients (pts) with locally advanced non-small cell lung cancer (NSCLC) benefit from combined modality therapy? a secondary analysis of RTOG 94-10. Int J Radiat Oncol Biol Phys. 2001;51(3):20-1.

21. Atagi S, Kawahara M, Yokoyama A, Okamoto H, Yamamoto N, Ohe Y, et al. Thoracic radiotherapy with or without daily low-dose carboplatin in elderly patients with non-small-cell lung cancer: a randomised, controlled, phase 3 trial by the Japan Clinical Oncology Group (JCOG0301). Lancet Oncol. 2012;13(7):671-8.

22. Jalal SI, Riggs HD, Melnyk A, Richards D, Agarwala A, Neubauer M, et al. Updated survival and outcomes for older adults with inoperable stage II non-small-cell lung cancer treated with cisplatin, etoposide, and concurrent chest radiation with or without consolidation docetaxel: analysis of a phase III trial from the Hoosier Oncology Group (HOG) and US Oncology. Ann Oncol. 2012;23(7):1730-8

23. Topkan E, Parlak C, Topuk S, Guler OC, Selek U. Outcomes of aggressive concurrent radiochemotherapy in highly selected septuagenarians with stage IIIB non-small cell lung carcinoma: retrospective analysis of 89 patients. Lung Cancer. 2013;81(2):226-30.

\section{Submit your next manuscript to BioMed Central and take full advantage of:}

- Convenient online submission

- Thorough peer review

- No space constraints or color figure charges

- Immediate publication on acceptance

- Inclusion in PubMed, CAS, Scopus and Google Scholar

- Research which is freely available for redistribution 